SAFE MEDICATION PRACTICES

\title{
Prograf and Advagraf Mix-up
}

Contributions to this column are prepared by the Institute for Safe Medication Practices Canada (ISMP Canada), a key partner in the Canadian Medication Incident and Prevention System. From time to time, ISMP Canada invites others to share learning based on local initiatives. The article presented here is reprinted, with permission, from the ISMP Canada Safety Bulletin 2009;9(5):1-2.

\section{INTRODUCTION}

$\mathrm{I}^{\mathrm{s}}$ SMP Canada received a report of a medication incident in which Advagraf (an extended-release formulation of tacrolimus for oral administration) was dispensed to a patient instead of the intended Prograf (an immediate-release oral formulation of the same drug). Recent reports from the United Kingdom ${ }^{1,2}$ and Europe $^{3,4}$ have documented mix-ups between Prograf and Advagraf and have outlined concerns about the outcomes of such incidents. According to these warnings, mix-ups between Prograf and Advagraf have led to serious harm, including cases of biopsy-confirmed acute rejection of transplanted organs and toxic effects due to overexposure. Although this incident occurred in a community pharmacy, it is an important alert for hospital pharmacists about the potential for serious patient harm if these drugs are mistakenly interchanged.

\section{MEDICATION INCIDENT REPORTED TO ISMP CANADA}

A patient who had undergone renal transplantation received a prescription refill from her community pharmacy for Prograf $1 \mathrm{mg}$ to be taken every 12 hours. Advagraf $1 \mathrm{mg}$ was dispensed with instructions for twice-daily dosing. Fortunately, the patient recognized that the capsules in the prescription bottle she had received had a different appearance from those in her previous prescription. The patient contacted her transplant program, and it was determined that Advagraf had been dispensed instead of the prescribed Prograf.

\section{CONTRIBUTING FACTORS}

The following factors were identified as potential underlying causes of this mix-up:

- The pharmacist believed that Advagraf was therapeutically interchangeable with Prograf.

- The name Advagraf did not suggest to the pharmacist that it was an extended-release product.
- The pharmacist had not seen any information about the availability of a new and different formulation of tacrolimus (i.e., Advagraf).

\section{BACKGROUND INFORMATION}

Prograf was approved for use in Canada in December 1995..$^{5}$ It is indicated for the prevention of organ rejection in patients who have received allogeneic liver, kidney, or heart transplant and for the treatment of refractory rejection in patients who have received allogeneic liver or kidney transplants, as well as for treating some cases of rheumatoid arthritis in adults. ${ }^{6}$ Advagraf was approved for use in Canada in October $2007^{5}$ and was made available on the market in April 2008. It is indicated for the prevention of organ rejection in adult patients who have received allogeneic kidney transplant. ${ }^{8}$ Both Prograf and Advagraf contain the immunosuppressant tacrolimus; however, Prograf is an immediate-release formulation to be taken every 12 hours when used for the prevention of organ rejection, whereas Advagraf is an extendedrelease formulation that is to be taken every 24 hours. ${ }^{6,8}$ Tacrolimus has a narrow therapeutic index and highly variable pharmacokinetics; it requires individualized dosing based on the results of careful therapeutic monitoring. It is imperative that Prograf and Advagraf be prescribed, dispensed, and taken correctly to ensure that blood levels of tacrolimus are maintained within the therapeutic range..$^{6,8}$

The following attributes may increase the potential for a mix-up between Prograf and Advagraf: the 2 formulations contain the same generic medication (tacrolimus); both medications are indicated for use after organ transplantation; both are available in a capsule format, for oral use, in the same dosage strengths $(0.5 \mathrm{mg}, 1 \mathrm{mg}$, and $5 \mathrm{mg})$; the product names are similar, both ending in "graf"; the two drugs are produced by the same manufacturer; and Prograf may be prescribed daily (for the treatment of rheumatoid arthritis), rather than twice daily, such that dosing frequency may not provide a cue as to which medication is intended. 


\section{MEDICATION INCIDENTS REPORTED INTERNATIONALLY}

ISMP Canada reviewed 33 medication incidents involving these drugs that have been reported internationally. In most of these incidents, the mix-up between Prograf and Advagraf occurred during prescribing and/or dispensing. The following common themes were identified from these error reports:

- Practitioners believed that Prograf and Advagraf were completely interchangeable, dose for dose.

- Orders using the generic name "tacrolimus", without the appropriate brand name, led to misinterpretation during dispensing.

- Some computerized pharmacy order screens listing these medications by the generic name tacrolimus placed Prograf and Advagraf on the same selection screen.

- Many of the errors that have been detected were caught by the patients, who noticed a difference in the appearance of the capsule and questioned a health care practitioner.

\section{RECOMMENDATIONS}

The following recommendations and considerations are provided:

- Add prominent descriptors for Prograf (e.g., "IMMEDIATE release") and Advagraf (e.g., "EXTENDED release") wherever these names appear, including on the drug selection screens of prescribing and dispensing information systems and in storage locations.

- Consider an automated alert for computerized prescriber and pharmacy order entry systems that includes information such as the following:

- Prograf and Advagraf are NOT interchangeableswitching a patient from one drug to the other requires the close supervision of a transplant specialist.

- Prograf is dosed every 12 hours for prevention of organ rejection (and is dosed daily for rheumatoid arthritis), whereas Advagraf is dosed every 24 hours for prevention of organ rejection.

- Include the brand name throughout the medication-use process.

- Actively involve patients (and family members as applicable) in the medication-use process. Educate patients about the potential for this mix-up to occur.

- Instruct patients to ask questions if they notice any unexplained changes in the appearance of their medication or its packaging. Consider including information about the potential for this mix-up in any printed drug information provided to patients.

- Share this article widely to alert practitioners to the potential for this mix-up and to provide an opportunity for proactive implementation of safeguards to prevent similar incidents in the future.

ISMP Canada has informed Health Canada about the Canadian report received and the information highlighted in this article. Astellas Pharma Canada Inc, the manufacturer of both Prograf and Advagraf, is also aware of these issues and is supportive of ISMP Canada sharing this information. Astellas Pharma Canada Inc is working to implement various measures to reduce the potential for mix-ups between Prograf and Advagraf.

\section{References}

1. Tacrolimus (Advagraf and Prograf): risk of serious medication errors. Drug Saf Update 2009 Jan [cited 2009 Apr 4];2(6):4-5. Available from: http://www.mhra.gov.uk/home/idcplg?IdcService=GET_FILE\& $\mathrm{dDocName}=\mathrm{CON} 035990 \&$ RevisionSelectionMethod $=$ Latest

2. Woywodt A, Delargy M, Thain Z. Different preparations of tacrolimus and medication errors [letter]. Am J Transplant 2008 [cited 2009 Apr 4];8:1962. Available from: http://www.alexander-woywodt.com/ fileadmin/www.alexander-woywodt.com/papers/letter_AJT.pdf

3. Advagraf: procedural steps taken and scientific information after the authorisation. London (UK): European Medicines Agency; 2009 [cited 2009 Apr 7]. p 1. Available from: http://www.emea.europa.eu/ humandocs/PDFs/EPAR/advagraf/H-712-en8.pdf

4. European Medicines Agency, Committee for Medicinal Products for Human Use. November 2008 plenary meeting monthly report. London (UK): European Medicines Agency; 2008 Nov 27 [cited 2009 Apr 7]. p 3. Available from: http://www.emea.europa.eu/pdfs/human/press/pr/ 61207408en.pdf

5. Health Canada, Drugs and Health Products. Notice of compliance database. Ottawa (ON): Health Canada; [cited 2009 Apr 6]. Available from: http://205.193.93.51/NocWeb/nocqrye.jsp Search terms used: Prograf and Advagraf.

6. Immunology Prograf [product monograph]. Markham (ON): Astellas Pharma Canada Inc; revised 2006 Oct 27 [cited 2009 Apr 6]. Available from: http://www.astellas.com/ca/en/immunology_prograf_PM.html

7. Advagraf ${ }^{\text {TM }}$ (extended release tacrolimus) is now available in Canada for kidney transplant patients [press release]. Markham (ON): Astellas Pharma Canada Inc; 2008 Apr 14 [cited 2009 Apr 7]. Available from: http://www.astellas.com/ca/en/press_releases_14.html

8. Immunology Advagraf [product monograph]. Markham (ON): Astellas Pharma Canada Inc; 2007 Oct 9 [cited 2009 Apr 6]. Available from: http://www.astellas.com/ca/en/immunology_advagraf_PM.html

\section{Acknowledgements}

ISMP Canada gratefully acknowledges the expert review of this article by (in alphabetical order): Patti Cornish, RPh, BScPhm, Patient Safety Service, Sunnybrook Health Sciences Centre; Jennifer Harrison, BScPhm, MSc, Pharmacy Clinical Site Leader, University Health Network; Nicola Rosaasen, BSC, BSP, Pharmacist, Saskatchewan Transplant Program; Jeffrey Schiff, MD, FRCPC, Multi-Organ Transplant Program, Toronto General Hospital; John W Senders, PhD, Professor Emeritus, University of Toronto; Anita Wong, BScPharm, Rexall Outpatient Pharmacy, University of Alberta Hospital; and Ken Wou, BSc(Pharm), pharmacy consultant.

\footnotetext{
Medication incidents (including near misses) can be reported to ISMP Canada in 1 of 2 ways:

- through the secure web portal at http://www.ismp-canada.org/ err_report.htm

- by telephone at 416.733 .3131 or toll-free at 1.866.544.7672 (1.866.54.ISMPC)
} 